\title{
Pendampingan Pemanfaatan lahan Pekarangan Di Desa Banjararum Kecamatan Kalibawang Kabupaten Kulon Progo
}

\author{
Silvi Nur Oktalina ${ }^{\mathbf{1}^{*}}$, Wiyono ${ }^{2}$, Rochmad Hidayat ${ }^{3}$ \\ 1,2,3 Program Studi Pengelolaan Hutan, Departemen Teknologi Hayati dan Veteriner Sekolah \\ Vokasi, Universitas Gadjah Mada \\ *Email: silvi.nuroktalina@ugm.ac.id
}

\begin{abstract}
Abstrak
Pekarangan merupakan lahan yang berada di sekitar rumah. Lahan ini banyak dimanfaatkan oleh para pemiliknya untuk menanam tanaman pertanian, perkebunan, buah-buahan dan tanaman kayu secara tumpangsari. Luas kepemilikan pekarangan di Kabupaten Kulon Progo relatif sempit, namun masyarakat mempunyai kearifan lokal untuk memanfaatkan lahan pekarangan dengan mengkombinasikan berbagai jenis tanaman sehingga dapat memberikan hasil dan menambah pendapatan keluarga. Kegiatan pengabdiakan kepada masyarakat ini dilakukan dengan tujuan untuk memberikan pendampingan masyarakat Desa Banjararum dalam memanfaatkan lahan pekarangan sehingga dapat lebih produktif dengan keterbatasan luas lahan yang diiliki masyarakat. Kegiatan ini dilakukan melalui pelatihan pemanfaatan lahan pekarangan dengan budidaya tanaman pertanian secara teori dan selanjutnya mempraktekan pengetahuan yang telah didapat dengan membuat demplot. Pembuatan demplot difokuskan di dusun Dondong sebagai daerah percontohan. Penguatan jaringan pemasaran dilakukan melalui kerja sama dengan PT East West Indonesia sebagai salah satu produsen bibit tanaman pertanian. Hasil kegiatan pengabdian masyarakat ini adalah meningkatnya pengetahuan masyarakat Desa Banajararum dalam memanfaatkan lahan pekarangan sehingga dapat menambah pendapatan keluarga. Masyarakat juga meperoleh jaringan baru dari produsen bibit yang terlibat dalam kegiatan pengabdian kepada masyarakat ini.
\end{abstract}

Kata Kunci: pekarangan, pelatihan, pemasaran, demplot

\begin{abstract}
Home garden is a land that is around the house. Home garden is widely used by the owners to plant crops, plantations, fruits and timber crops. Plantation in home garden usually in intercropping. The width of the ownership of the homegarden in Kulon Progo Regency is relatively narrow, but the community has local wisdom to utilize the home garden by combining various types of plants so that it can give the result and increase the family income. This community devotion activity is done with the aim to give assistance of Banjararum Village community in utilizing home garde so that it can be more productive with limited area of land owned by society. This activity is done through training the utilization of home garden with cultivation of agricultural crops in theory and then practice the knowledge gained by making demonstration plot. The demonstration plot is focused in Dondong hamlet as a pilot area. Strengthening the marketing network is done in cooperation with PT East West Indonesia as one of the producers of agricultural crops. The result of this community service activity is the increasing knowledge of the people of Desa Banjararum in utilizing the yard land so that it can increase the family income. The community also acquired a new network of seed producers involved in community service activities.
\end{abstract}

Keywords: homegarden, training, marketing, demplot 


\section{PENDAHULUAN}

Desa Banjararum yang merupakan kawasan agropolitan ini mempunyai potensi sumber daya alam yang melimpah. Beberapa dusun di desa ini mempunyai pemandangan alam yang sangat indah dengan kehidupan dan cara hidup masyarakat yang sangat menarik. Lokasi desa di perbukitan menoreh dengan ketinggian yang cukup tinggi menjadikan kondisi desa ini cukup sejuk dan sangat nyaman. Desa ini merupakan salah satu desa terluas di Kabupaten Kulon Progo dengan jumlah pedukuhan sebanyak 26 buah dan 9 diantaranya berada di daerah perbukitan. Desa Banjararum memiliki potensi di sektor pertanian, sebagai daerah penghasil durian, rambutan, cengkeh, dan kakao selain sebagai penghasil padi dari lahan pertanian dengan irigasi seluas 360 ha dan lahan tadah hujan.

Selain obyek sumber daya alam yang sudah terbentuk, Desa Banjararum mempunyai potensi pertanian dan cara hidup petani yang dapat digunakan sebagai daya tarik desa ini. Produk pertanian yang mempunyai potensi cukup bagus adalah kakao, pisang, padi, singkong dan kelapa. Selain potensi pertanian Desa Banjararum juga mempunyai potensi ternak. Hampir setiap keluarga memiliki hewan ternak. Namun tidak ada warga yang secara khusus bergantung pada hasil peternakan. Masyarakat menganggap hewan ternak, khususnya sapi sebagai tabungan.

Dengan potensi pertanian, peternakan dan sumber daya alam lainya perlu intensifikasi pemanfaatan lahan yang ada. Lahan yang banyak dimiliki masyarakat desa Banjararum adalah lahan pekarangan. Pemanfaatan lahan pekarangan untuk kegiatan produktif selain dapat meningkatkan ekonomi keluarga juga dapat meningkatkan ketahanan pangan masyarakat dan memanfaatkan produk lokal unggulan desa. Berdasarkan analisis situasi dan kondisi Desa Banjararum maka perlua dilakukan identifikasi dan intensifikasi pemanfaatan lahan pekarangan, pengaturan komposisi jenis tanaman di lahan pekarangan dan penguatan lembaga pemasaran hasil tanaman lahan pekarangan melalui peningkatan jaringan pemasaran sehingga dapat memberikan tambahan pendapatan bagi masyarakat di Desa Banjararum.

Kegiatan pengabdian kepada masyarakat dengan pemanfaatan lahan pekarangan ini merupakan salah satu solusi yang dapat dilakukan untuk meningkatkan pendapatan masyarakat di Desa Banjararum, selain itu juga merupakan lahan pekerjaaan yang dapat dimanfaatkan oleh para warga masyarakat untuk meningkatkan penghidupannya. Beberapa kegiatan yang dilakukan dalam pemanfaatan lahan pekarangan antara lain mengkombinasikan jenis tanaman pertanian, perkebunan dan pohon dalam satu lahan, penanaman tanaman sayursayuran pada media dengan polybag, pemanfaatan limbah tanaman pertanian sebagai media tanam dan memperkuat jaringan pemasaran hasil tanaman pekarangan. Adapun luaran yang dihasilkan dari kegiatan pengabdian kepada masyarakat ini adalah meningkatnya pengetahua masyarakat dalam memanfaatkan lahan pekarangan sehingga mempunyai nilai ekonomi dan menambah pendapatan bagai keluarga.

\section{METODE}

Lokasi kegiatan program pengabdian kepada masyarakat pada tahun 2017 adalah desa Banjararum Kecamatan Kalibawang Kabupaten Kulon Progo. Lokasi ini berjarak kurang leih $243 \mathrm{~km}$ dan dapat ditempuh dalam waktu 1 jam dari UGM. Peta lokasi desa disajikan dalam Gambar 1

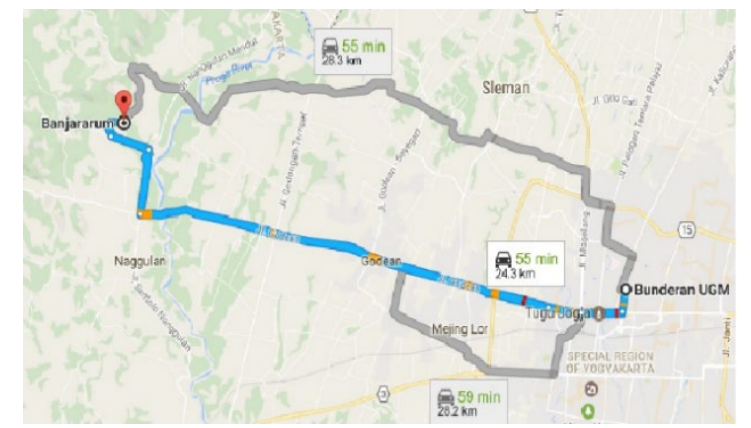

Gambar 1. Lokasi desa Banjararum 
Tabel 2. Deskripsi kegiatan dan metode kegiatan pengabdian kepada masyarakat

\begin{tabular}{ll}
\hline \multicolumn{1}{c}{ Kegiatan } & \multicolumn{1}{c}{ Metode } \\
\hline $\begin{array}{l}\text { Identifikasi dan intensiikasi pemanfaatan } \\
\text { lahan pekarangan di Desa Banajararum }\end{array}$ & $\begin{array}{l}\text { Informasi pemanfaatan lahan pekarangan } \\
\text { diperoleh melalui observasi lapangan, focus } \\
\text { group disccussion dan wawancara mendalam } \\
\text { dengan tokoh-tokoh kunci }\end{array}$ \\
$\begin{array}{l}\text { Penanaman tanaman sayur-sayuran pada } \\
\text { media dengan polybag }\end{array}$ & $\begin{array}{l}\text { Penanaman tanaman sayur-sayuran pada } \\
\text { media dengan polybag }\end{array}$ \\
$\begin{array}{l}\text { Pemanfaatan limbah tanaman pertanian } \\
\text { sebagai media tanam }\end{array}$ & $\begin{array}{l}\text { Pelatihan dan praktek pengolahan limbah } \\
\text { tanaman pertanian }\end{array}$ \\
$\begin{array}{l}\text { Meperkuat jaringan pemasaran hasil } \\
\text { tanaman lahan pekarangan }\end{array}$ & Pelatihan dan peningkatan jaringan \\
\hline
\end{tabular}

\section{HASIL DAN PEMBAHASAN}

Kawasan agropolitan merupakan kawasan yang tumbuh dan berkembang karena berjalannya sistem dan usaha agribisnis serta mampu melayani dan mendorong, menarik dan menghela kegiatan pembangunan pada sektor pertanian dalam arti luas. Kawasan agropolitan merupakan kawasan yang memiliki potensi hasil pertanian, perkebunan, kehutanan (Community Forest), peternakan, dan perikanan. Sumber daya alam yang tersedia pada kawasan agropolitan dapat ditingkatkan dengan pemanfaatan lahan yang efektif dan efisien seperti lahan pekarangan. Kebanyakan masyarakat pada umumnya tidak memanfaatkan lahan pekarangan secara maksimal. Maka dari itulah kegiatan pelatihan pemanfaatan lahan pekarangan sangat diperlukan.

Tahapan pelaksanaan kegiatan pendampingan pemanfaatan lahan pekarangan di Desa Banjararum Kecamatan Kalibawang Kabupaten Kulon Progo dimulai dari:

a. Koordinasi dengan pemerintah desa Koordinasi dengan pemerintah desa sangat diperlukan karena selanjutnya informasi mengenai pelatihan akan lebih mudah tersampaikan kepada masyarakat desa. Peran perangkat desa juga sangat diperlukan dalam mengarahkan masyarakat desa untuk lebih proaktif dalam kegiatan Pengabdian Kepada Masyarakat.

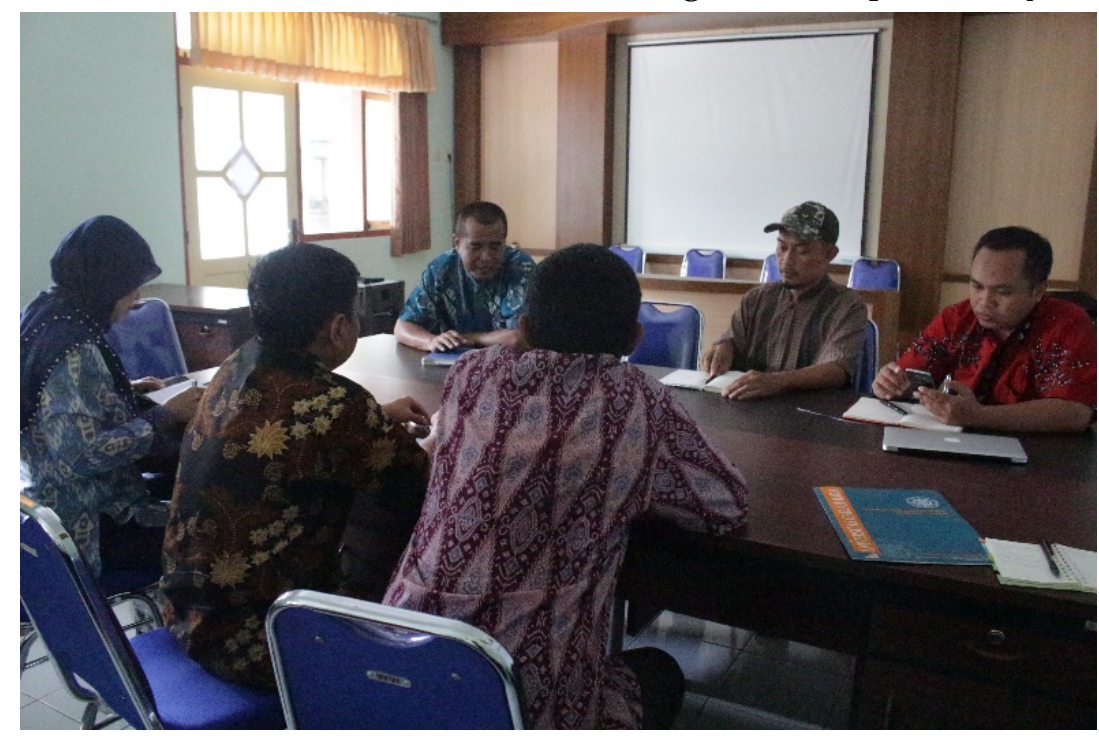

Gambar 2. Koordinasi dengan pemerintah

Desa Banjararum Kecamatan Kalibawang (6 Juli 2017) 
Koordinasi dilaksanakan di Kantor Kelurahan Banjararum pada tanggal 6 Juli 2017. Bersama dengan anggota perangkat desa Banjararum koordinasi mengenai kegiatan pengabdian masyarakat yang akan dilaksanakan meliputi pemanfaatan lahan pekarangan, pemanfaatan untuk kawasan wisata dan potensi lain yang dapat dikembangkan di kawasan agropolitan khususnya Desa Banjararum. Salah satu dayatarik yang sedang dikembangkan adalah adanya lokasi wisata Punthuk Ngepoh yang berada di Desa Banjararum. Lokasi wisata tersebut menyajikan pemandangan alam dari daerah pegunungan dan dihiasi bunga-bunga. Pada kegiatan koordinasi ini disepakati dilakukan kegiatan pelatihan dan pembuatan demplot bagi masyarakat untuk memanfaatkan lahan pekarangannya sehingga mempunyai nilai tambah dan dapat meningkatkan pendapatan keluarga.

b. Sosialisasi program pelatihan
Sosialisasi mengenai kegiatan Pelatihan Pemanfaatan Lahan Pekarangan dilaksanakan pada tanggal 31 Juli 2017 kepada tokoh masyarakat seperti perwakilan kelompok tani, perwakilan tarang taruna beserta perangkat desa. Melalui kegiatan sosialisasi ini diharapkan masyarakat, tokoh masyarakat dan perangkat desa dapat memahami maksud dan tujuan dilakukan kegiatan pengabdian kepada masyarakat ini dan mensinergiskan kegiatan ini dengan kegiatan-kegiatan lain yang telah dirancanakan pihak desa melalui musyawarah perencanaan dan pengembangan desa.

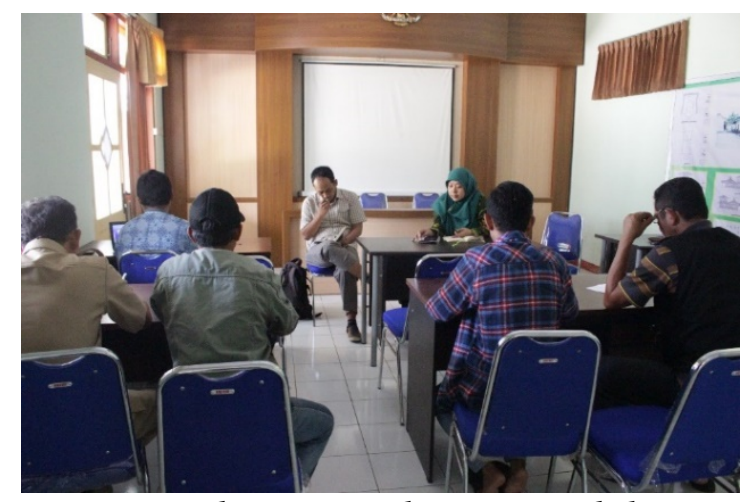

Gambar 3. Sosialisasi Pengabdian Kepada Masyarakat (31 Juli 2017) c. Pelatihan budidaya tanaman sayuran bekerjasama dengan PT. East West Indonesia

Pelatihan pemanfaatan lahan pekarangan bekerjasama dengan PT. East West Indonesia yang merupakan perusahaan benih sayur terpadu di Indonesia yang menghasilkan benih unggul sayuran melalui kegiatan pemuliaan tanaman. Perusahaan ini memiliki tujuan untuk mengembangkan industri benih lokal yang canggih untuk menghasilkan benih sayur yang berkualitas tinggi. Kerjasama ini dilakukan untuk melatih masyarakat desa agar mampu memproduksi sayur maupun benih sayur secara mandiri pada lahan pekarangan yang dimiliki. Harapannya adalah sayur yang dihasilkan adalah kualitas unggul dan dapat meningkatkan kesejahteraan masyarakat desa.

\section{d. Praktek di Dusun Dondong Desa Banjararum \\ Pelatihan pemanfatan lahan} pekarangan dilaksanakan di Dusun Dondong Desa Banjararum pada tanggal 28 Agustus 2017. Pelatihan ini bertujuan untuk meningkatkan pengetahuan masyarakat mengenai teknologi pembibitan berbagai jenis sayur yang dapat dikembangkan di lahan pekarangan. Materi tersebut disampaikan langsung kepada masyarakat desa yang ikut serta dalam pelatihan pemanfaatan lahan pekarangan. Masyarakat yang ikut serta pada pelatihan pemanfaatan lahan pekarangan kurang lebih 10 sampai dengan 12 orang. Hal tersebut dikarenakan rumah penduduk yang letaknya berjauhan pada satu desa.

Pertambahan penduduk dan pembangunan di banyak sektor mendorong perubahan pemanfaatan lahan pertanian menjadi pemukiman, industri, pusat bisnis dan perkantoran. Makin berkurrangnya area hijau dan penambahan sarana dan prasarana untuk menunjang aktifitas manusia seringkali menimbulkan polutan yang sebenarnya merugikan manusia. Banyak cara untuk mengantisipasi dampak polusi dari hal-hal yang sulit hingga yang cukup mudah. Salah satu cara adalah 
memanfaatkan lahan sekitar rumah untuk budidaya tanaman yang sederhana melalui konsep pertanian perkotaan (Urban Farming), seperti Vertikultur dan Hidroponik.

Masyarakat dikenalkan dengan berbagai jenis varietas tanaman sayur buah, sayur daun, dan sayur rambat. Kemudian mereka juga diperkenalkan berbagai jenis media tumbuh yang dapat digunakan untuk membudidayakan tanaman sayur (Gambar 4). Media dapat diperoleh dari lingkungan sekitar seperti tanah, pupuk kandang dan masyarakat diberi pengetahuan mengenai teknik persemaian tanaman sayur yang baik dan benar (Gambar 5.). Teknik persemaian meliputi waktu tanam, jarak tanam sayurmayur, dan sistem tanam. Pengetahuan selanjutnya yang dibagikan adalah teknik pemeliharaan tanaman sayur yang meliputi teknik penyiraman, interval penyiraman, teknik pemupukan, dan pengenalan jenis pupuk baik organik maupun non organik, perlindungan dari hama dan penyakit hingga pemanenan.



Gambar 4. Pengenalan media tanam

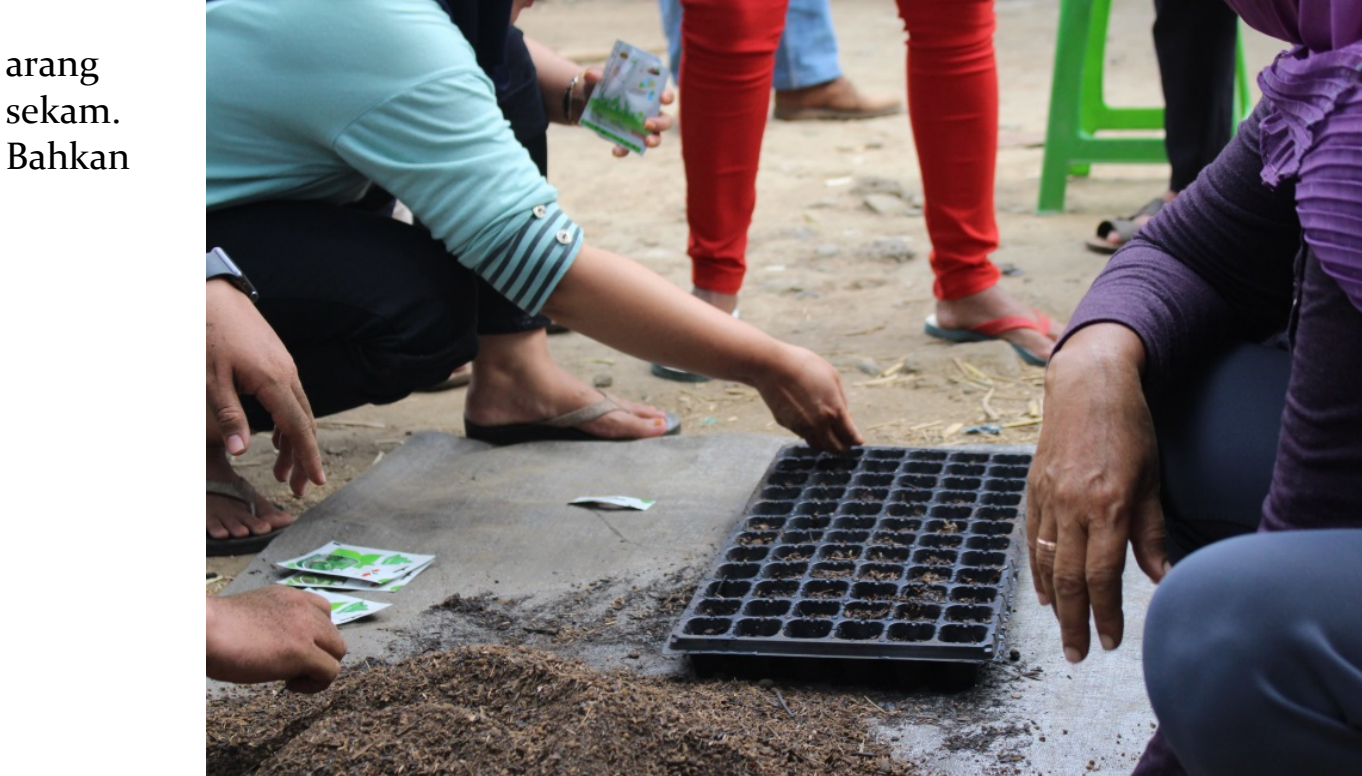

Gambar 5. Teknik penaburan benih pada potray yang telah diisi media tanam 
Selain metode pembuatan tanaman sayur pada lahan pekarangan, masyarakat juga dikenalkan teknik pembuatan pupuk hayati yang dapat dibuat di lahan pekarangan. Pupuk hayati yang dapat dibuat adalah Pupuk Tricoderma. Pupuk Tricoderma adalah pupuk dari bahan organik (sampah organik) bisa dari seresah dedaunan, jerami, sampah rumahtangga organik dan lain-lain yang ditambahkan jamur Tricoderma yang berfungsi untuk menguraikan bahan organik menjadi pupuk organik. Bahan lain yang digunakan untuk membuat pupuk tricoderma antara lain kotoran ayam, pupuk urea, pupuk TSP, dan dolomit.

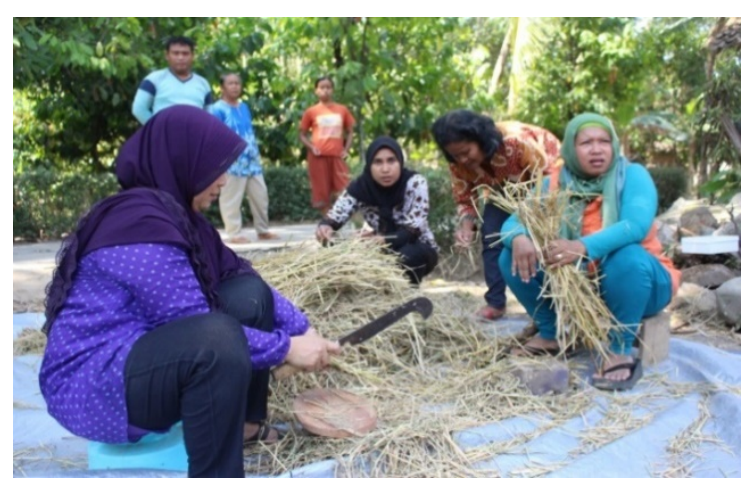

(a) $\mathrm{mi}$
Dalam $1 \mathrm{~m}^{3}$ bahan yang digunakan untuk membuat pupuk hayati akan menghasilkan sekitar 6o kg pupuk. Manfaat pupuk Tricoderma adalah untuk menjaga kesuburantanah, melindungi perakaran tanaman dari penyakit, menggemburkan tanah dll. Metode pembuatan pupuk tricoderma sangatlah mudah sehingga masyarakat desa dapat mempraktekannya di sekitar lahan pekarangan yang dimiliki. Langkah-langkah pembuatan pupuk tricoderma dapat dilihat pada gambar 6 . Persiapan bahan utama (jerami a, kotoran ayam b).

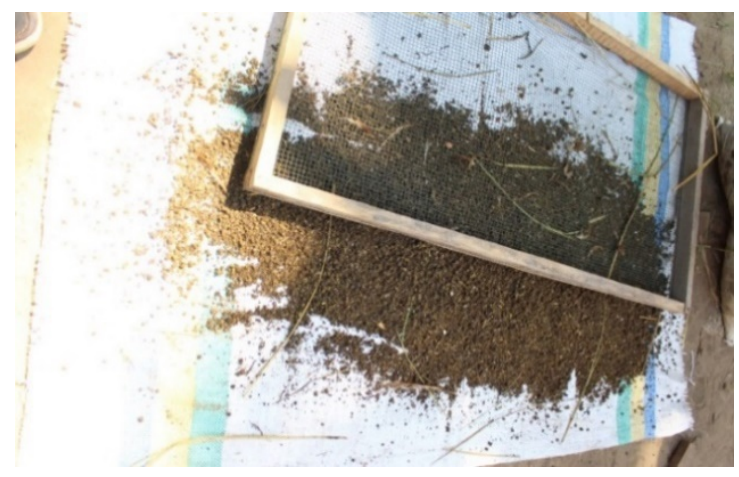

(b) Kotoran ayam

Gambar 6. Bahan Baku pupuk Tricoderma

Sebelum digunakan jerami harus dipotong kecil-kecil fungsinya adalah agar penguraian bahan organik lebih cepat. Sedangkan untuk kotoran ayam harus diayak lembut agar lebih mudah saat dibuat adonan. Pada Gambar 7. Pembuatan adonan. Tricoderma yang terdiri dari urea $500 \mathrm{~g}$, TSP $300 \mathrm{~g}$, dolomit $500 \mathrm{~g}$ dan jamur
Tricoderma $1 \mathrm{Kg}$. Semua bahan harus dalam kondisi halus agar mudah untuk dicampur. Kemudian adonan dibagi 4 sama rata (dilihat pada gambar 8.) untuk masingmasing bagian akan dicampurkan pada $5 \mathrm{Kg}$ kotoran ayam yang telah diayak sebelumnya. 

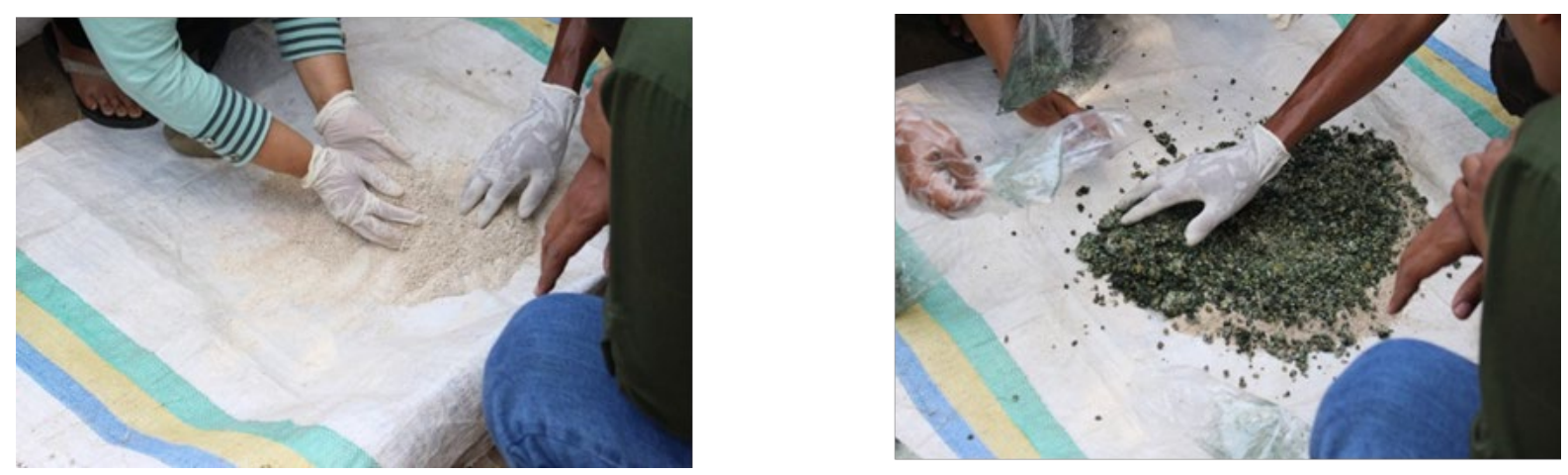

Gambar 7. Pembuatan adonan Tricoderma
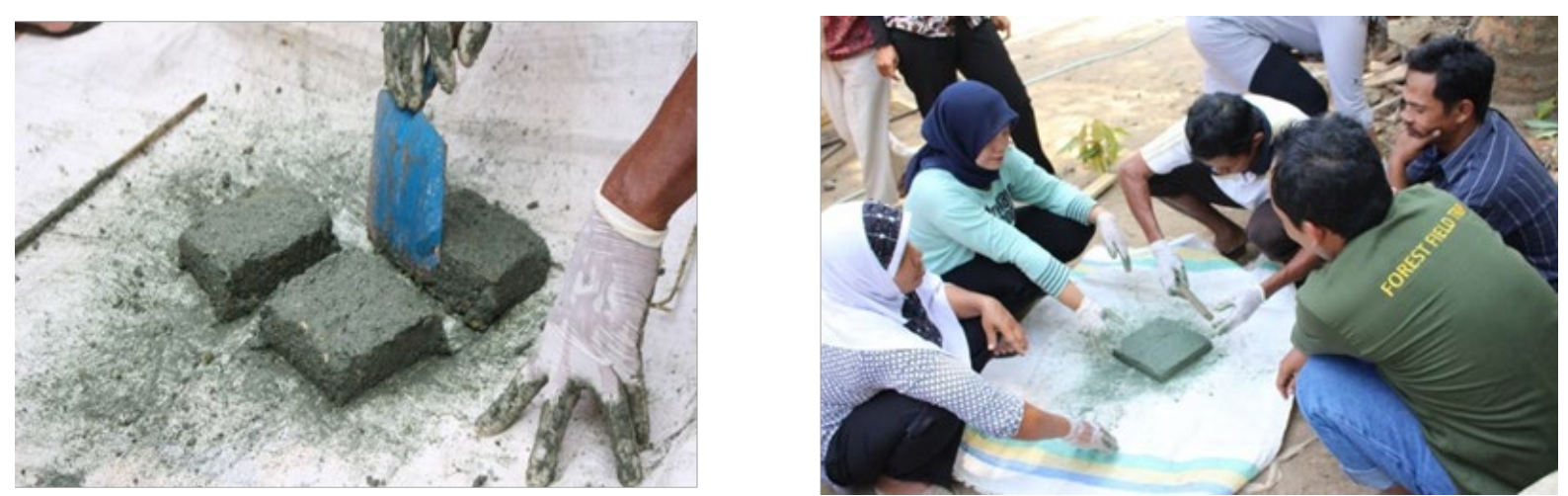

Gambar 8. Adonan dibagi empat bagian yang sama

Setelah semua adonan siap bahan baku jerami dimasukkan kedalam tempat pembuatan pupuk hayati yang berukuran $1 \mathrm{x}$

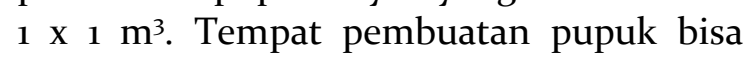
dibuat dari bahan kayu, bambu ataupun dibuat permanen dengan bahan semen dan batu bata. Jerami dimasukkan bertahap untuk lapisan pertama dengan tinggi $25 \mathrm{~cm}$

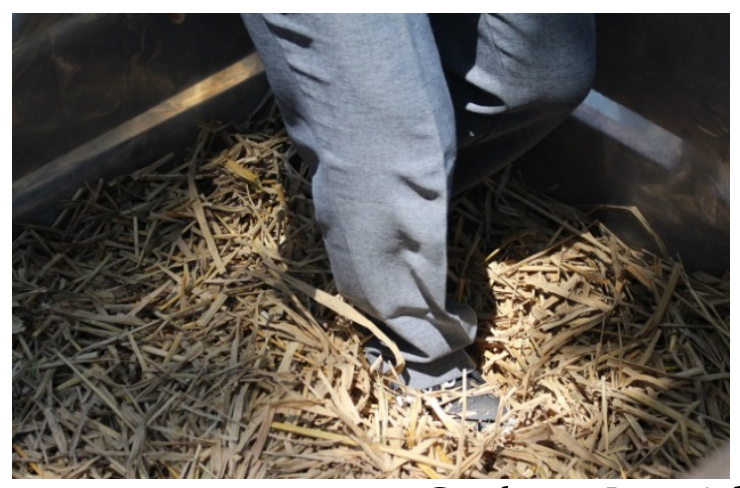

dipadatkan (Gambar 9.). Setelah itu masukkan adonan kotoran ayam dengan tricoderma yang sudah disiapkan. Selanjutnya lapisan pertama disiram air hingga jenuh. Ulangi hal tersebut untuk setiap lapisan hingga bak penampungan penuh seperti pada Gambar 10.

Gambar 9. Jerami dipadatkan dengan cara diinjak 



Gambar 10. Bak penampungan $1 \mathrm{~m}^{3}$ penuh

Jika bak penampungan sudah mulai penuh langkah selanjutnya adalah menutup rapat bak penampung agar proses penguraian bahan organik oleh jamur tricoderma dapat berlangsung. Setiap hari bahan harus disiram dengan air hingga jenuh selama kurang lebih 2 minggu. Setelah itu didiamkan sampai pupuk jadi atau terurai dengan sempurna. Proses penguraian berkisar 1 bulan hingga 2 bulan tergantung dari bahan baku yang digunakan.

Pengetahuan mengenai pemanfaatan lahan pekarangan diharapkan mampu menjadi solusi permasalahan ekonomi dan sosial masyarakat desa dan mampu meningkatkan kesejahteraan masyarakat desa di wilayah agropolitan.

\section{e. Kegiatan monitoring}

Dalam kegiatan pendampingan tentu perlu dilakukan monitoring terhadap perkembangan masyarakat desa Banjararum. Monitoring bertujuan untuk melihat apakah program pelatihan memberikan dampak positif pada masyarakat desa dan juga untuk mengidentifikasi permasalahan lain maupun yang baru muncul setelah adanya kegiatan pelatihan. Selanjutnya dapat ditindaklanjuti dengan kegiatan pendampingan yang berkesinambungan. Jadwal monitoring Pendampingan Pemanfaatan Lahan Pekarangan di Desa Banjararum Kalibawang Kulon Progo dilaksanakan pada bulan September 2017. f. Ekspo Pengabdian Kepada Masyarakat Ekspo pengabdian kepada masyarakt bertujuan untuk memberikan informasi kepada masyarakat umum, mahasiswa maupun media mengenai kegiatan yang dilaksanakan oleh Sekolah Vokasi dengan harapan dapat menambah pengetahuan yang bermanfaat secara nyata dilapangan. Selain kegiatan ini dilakukan untuk memberikan ide-ide baru kepada masyarakat secara umum untuk memajukan dan meningkatkan kesejahteraan bangsa.

\section{SIMPULAN}

Berdasarkan kegiatan pengabdian kepada masyarakat yang telah dilakukan dan monitoring maka dapat disimpulkan bahwa pengetahuan masyarakat dalam memanfaatkan lahan pekarangan telah meningkat melalui upaya pelatihan dan pembuatan demplot. Terciptanya jaringan dengan produsen bibit yang juga meningkatkan jaringan pemasaran hasil tanaman pekarangan dengan keterlibatan PT East West Indonesia.

\section{DAFTAR PUSTAKA}

Desa Banjararum. (2017). Anggaran Pendapatan dan Belanja Desa Banjararum Kecamatan Kalibawang Kabupaten Kulon Progo DI Yogyakarta

Desa Banjararum. (2017). Profil desa Banjararum Kecamatan Kalibawang Kabupaten Kulon Progo DI Yogyakarta 
BPS Kulon Progo. (2016). Kabupaten Kulon

Progo dalam Angka 2016. Badan Pusat

Statistik Kabupaten Kulon Progo. 